\title{
Avaliação do teor de flúor na água de abastecimento e sua retenção pelos filtros domésticos
}

\author{
Evaluation of the fluoride level on the water of supplying and its retention by domestic filters
}

\section{Virgílio Vilas Boas Fernandes Jr. ${ }^{1}$, Suely Carvalho Mutti Naressi², Symone Cristina Teixeira ${ }^{3}$, José Benedito Oliveira Amorin ${ }^{4}$,} Luciana Fortes Gama ${ }^{5}$

\section{Resumo}

O objetivo deste trabalho foi verificar o teor de flúor da água de abastecimento que chegava nas residências e analisar se ocorria alteração no nível de flúor após a água passar pelos reservatórios e filtros domésticos. As coletas de amostras de água foram feitas em residências do município de São José dos Campos, SP, e os resultados foram submetidos à análise estatística. Da análise dos resultados, pode-se concluir que $70 \%$ das amostras apresentaram nível de acordo com o preconizado como ideal para a localidade analisada e não houve evidência de alteração significativa dos níveis de flúor da água de abastecimento durante a passagem pelos reservatórios e filtros domésticos.

Palavras-chave: Flúor, Filtros domésticos, Fluoretação, Água de abastecimento

\section{Abstract}

This study tried to verify the fluoride level in water that supplies residences, if water has any fluoride level changes after passing to the domestic reservoirs domestic filters. Water samples had been obtained in São José dos Campos city. Results were submitted to statistical analysis. The results showed that $70 \%$ of the analyzed samples had its fluoride level according to what is recommended. There was not any evidence of significant alteration in fluoride levels of public supplied water in the reservoirs and domestic filters.

Keywords: Fluoride, Systems of water purification, Fuoridation, Water consumption
${ }^{1}$ Mestrando em Odontologia Restauradora na Faculdade de Odontologia da Universidade Estadual Paulista (UNESP), Campus de São José dos Campos

${ }^{2}$ Professora-Assistente Doutora da Faculdade de Odontologia da Universidade Estadual Paulista (UNESP), Campus de São José dos Campos

${ }^{3}$ Professora-Assistente Doutora da Faculdade de Odontologia da Universidade Estadual Paulista (UNESP), Campus de São José dos Campos

${ }^{4}$ Professor-Assistente Doutor da Faculdade de Odontologia da Universidade Estadual Paulista (UNESP), Campus de São José dos Campos

${ }^{5}$ Cirurgiã-Dentista, graduada pela Faculdade de Odontologia da Universidade Estadual Paulista (UNESP), Campus de São José dos Campos

Correspondência: Virgílio Vilas Boas

Endereço: Rua Enseada, 46 - Bairro: Cidade Jardim - CEP 12230-630 - São José dos Campos - SP

Email: virgiliovilas@ hotmail.com

\section{Introdução}

A fluoretação da água de consumo é considerada uma das maiores conquistas da saúde pública, principalmente por seu caráter democrático, uma vez que abrange uniformemente a população, independentemente do nível social e econômico. É o mais seguro, efetivo, simples e econômico método de prevenção da cárie dentária, e sua adoção em todas as áreas onde essa doença constitui-se em problema de saúde pública, tem sido uma recomendação insistentemente reiterada pelas organizações internacionais e nacionais do setor da saúde (BRASIL, 1974; BRASIL, 1975; BRASIL, 1976; BRASIL, 2004; BRASIL, 2006; VIDAL et al., 2006; WORLD HEALTH ORGANIZATION, 1994).

A Lei $n \div 6.050 / 74$, regulamentada pelo Decreto Federal $n$ $76.872 / 75$ e pela Portaria no ${ }^{\circ} 35 / B S B / 75$ do Ministério da Saúde, são instrumentos legais em vigor que disciplinam a obrigatoriedade da fluoretação em sistemas públicos de abastecimento de água no Brasil. A vigilância e o controle sobre a quantidade de flúor presente na água distribuída à população são exercidos em conformidade com a Portaria MS $n^{\circ}$ 518, de 25 de março de 2004, e com a Portaria n 635/BSB/75, que recomenda os limites de concentração do íon fluoreto em função da média das temperaturas máximas. Dessa forma, os teores de flúor "ótimos" para a prevenção da cárie dental devem ter, na maior parte do território brasileiro, 0,7mg de flúor por litro, permitindo variações de $0,1 \mathrm{mg}$ para mais ou para menos (BRASIL, 1974; BRASIL, 1975; BRASIL, 1976; BRASIL, 2004; BRASIL, 2006; VIDAL et al., 2006).

São José dos Campos, município do Estado de São Paulo, realiza a fluoretação da água de abastecimento desde 1976, com teor de flúor ideal entre 0,6 e 0,8 ppm, em função da temperatura média anual, tendo a Companhia de Saneamento Básico do Estado de São Paulo - Sabesp - como empresa responsável pelo tratamento e adequação da água para o abastecimento da população, bem como de mais da metade dos municípios deste Estado, possuindo laboratórios para análise com padrão de qualidade reconhecido internacionalmente (SABESP, 2007).

Quando da ingestão, o flúor é rapidamente absorvido pela mucosa gástrica, cai na corrente sanguínea e se deposita nos tecidos calcificados como ossos e dentes e sua excreção é feita principalmente pela urina, havendo também liberação através dos fluídos bucais, como a secreção salivar, e pelo suor, sendo que a parcela não absorvida é excretada pelas fezes. O flúor pode ser depositado também em tecidos moles e ser retido na placa dental ou sobre os dentes na forma de fluoreto de cálcio (CURY, 2001; KOZLOWSKI; PEREIRA, 2003). 
Durante o período de formação dos dentes, os íons flúor precipitam-se sobre os cristais de apatita, com ele reagindo de maneira a formar cristais de fluorapatita que são mais estáveis e mais resistentes à dissolução ácida do que a hidroxiapatita. No entanto, a ingestão de teores de flúor acima do ideal ou intoxicação crônica, durante a fase de formação dos dentes e por um prolongado período de tempo, determina a ocorrência da fluorose dental (KOZLOWSKI; PEREIRA, 2003; MASCARENHAS, 2000). Em face da possibilidade de ingestão de flúor proveniente de fontes outras que não somente da água de abastecimento - dentifrício, enxaguatórios, alimentos, fórmulas medicamentosas, entre outras, o controle desse teor tornase imperioso (CASARIN et al., 2007; KOZLOWSKI; PEREIRA, 2003; MASCARENHAS, 2000; RAMIRES et al., 2006).

Cury (2001) e Schulte, Rossbach e Tramini (2001), em estudos posteriores, comprovaram que a presença do flúor topicamente em contato com os tecidos mineralizados dos dentes tinha um efeito preponderante no controle da doença cárie, com redução de perda de mineral, interferindo diretamente na desmineralização do esmalte, tornando-o mais resistente aos ácidos bacterianos, aumentando ainda a capacidade da saliva em repor minerais perdidos pelos dentes.

Estudos também mostram que o íon flúor pode ser removido ou modificado no processo de purificação da água, podendo, da mesma forma, sofrer alterações em função da condição de armazenagem em caixas d'água e no trânsito pelas tubulações das residências, fatores estes que poderiam interferir no potencial efeito cariostático do flúor que chega às residências (BROWN; AARON, 1991; GLASS, 1991; JOBSON, 2000; ONG; WILLIANS; HOLT, 1996).

Segundo Glass (1991) existem oito tipos básicos de sistemas de purificação de água que podem remover fluoretos: através de filtro de carbono ativado, com simples ou dupla filtragem; troca de íns; troca de cátions; por desinfecção; por destilação; por filtração; por oxidação e por osmose reversa. Essa remoção pode constituir-se num fator de preocupação devido à popularização do uso de filtros.

Brown e Aaron (1991) viram que a redução no nível de fluoretos na água, após a passagem pelos sistemas de filtragem de água estudados, com destaque para os de carvão ativado e o sistema osmótico reverso, era significante. Existem marcas de filtros que utilizam sistema de dupla filtragem, com duas câmaras de carvão ativado, uma para a remoção de partículas sólidas maiores e a outra com a função germicida e de adsorção de cloro, embora persista o filtro de cântaro portátil como o modelo mais usado pela nossa população, devido à praticidade na limpeza e o baixo custo. Como o flúor é o elemento mais eletronegativo da tabela periódica, pode haver também a remoção desse ânion durante a remoção do cloro, nesse sistema de filtragem.

Em face da popularidade da utilização de filtros, maioria do tipo vela com carvão ativado, da diversidade de tipos de reservatórios de água comercializados na atualidade e da preocupação com a somatória das fontes de flúor, buscou-se averiguar o teor de flúor na água de abastecimento que chega aos domicílios e as variações de teor ocorridas desde a entrada da água fluoretada nas residências até o ponto de consumo.

\section{Materiais e Métodos}

As coletas de amostras de água foram feitas em 20 residências das 5 regiões (norte, sul, leste, oeste e centro) do município de São José dos Campos, SP, totalizando 100 domicílios de coleta, diversos e distantes dos pontos de coleta controle da Sabesp. O cálculo do número de domicílios foi feito por amostragem por cotas (não probabilístico), com sorteio para identificar uma rua em cada uma das cinco regiões, totalizando 5 ruas. As residências foram selecionadas por amostragem por conveniência tendo como ponto de partida a primeira casa número par da rua sorteada e, a seguir, as próximas 19, à medida que os moradores concordassem em participar e assinassem o termo de consentimento livre e esclarecido (BERNI, 2002). Também como condição para participar do levantamento, a residência deveria possuir um reservatório de água (caixa d'água), o abastecimento ser feito pelo sistema de distribuição de água pública realizado pela Sabesp e apresentar sistema de filtragem por ponto de uso, nas modalidades filtragem simples (o filtro contém apenas uma vela de carvão ativado anexado ao encanamento funcionando com uma torneira) ou o sistema de cântaro portátil (a água passa pelo reservatório de barro ou plástico que contém a vela, esta é coletada no cântaro e dispensada por dispositivo tipo torneira).

Em cada casa foram feitas 3 coletas de água, cada uma de $50 \mathrm{ml}$, sendo que a primeira coleta foi proveniente diretamente da rede de abastecimento público, na torneira existente no ponto de entrada, junto ao cavalete da Sabesp; a segunda, em torneira abastecida pelos reservatórios domiciliares (caixas d'água) no interior da residência e, a terceira, obtida após a filtragem por meio dos filtros domiciliares, totalizando assim as 3 amostras de cada residência (Figura 1), colhidas no mesmo dia e analisadas no dia subsequente.

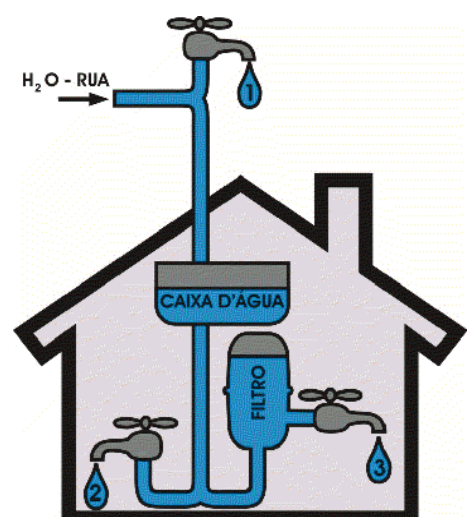

Figura 1. llustração dos pontos de coleta de água.

Os frascos plásticos de polietileno de $50 \mathrm{ml}$, adquiridos previamente limpos e higienizados, foram enxaguados com a mesma água a ser coletada, fechados hermeticamente e levados, ato contínuo, para análise. A identificação das amostras seguiu a ordem estabelecida numa planilha onde constavam endereço, pontos de coleta, tipo de reservatório e de filtro utilizado, dia e hora da coleta.

As amostras foram analisadas pelo laboratório físico-químico da Divisão de Controle Sanitário da Companhia de Saneamento Básico do Estado de São Paulo - Sabesp -, através de um Medidor de Ílons Iso Meter - Orion - Modelo 720 A, pelo método eletrométrico, por ser o mais preciso $(0,01 \mathrm{mg} / \mathrm{l})$, exato $(99,9 \%)$ e sofrer menos influência das impurezas das amostras coletadas (AMORIM, 1995; ELDSTEIN, 1992; ROBINSON; DAVIES; WILLIANS, 1991; VIDAL, 2006). A concentração de flúor presente nas amostras de água foi determinada em duplicata, utilizando-se um eletrodo íon sensível, acoplado a um potenciômetro (Procyon, modelo 720), com $1,0 \mathrm{ml}$ da amostra, a qual foi adicionado $1,0 \mathrm{ml}$ de TISAB II (Orion). Previamente à análise, foi feita uma calibração em triplicata, com

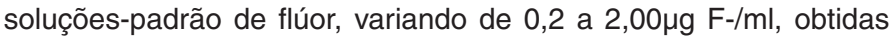
por diluição seriada a partir de um estoque-padrão contendo $100 \mu \mathrm{g}$ $\mathrm{F}-/ \mathrm{ml}$ (Orion) e também foram realizados ainda testes com conccentrações conhecidas de flúor, a cada hora, para checar-se a calibração (SABESP, 2007).

As leituras obtidas em $\mathrm{mV}$ foram aplicadas a uma planilha de cálculos (Microsoft Excel), contendo os dados dos padrões com concentrações conhecidas de flúor, convertidas para mg de flúor. Somente curvas de calibração com variação de no máximo $5 \%$ foram aceitas. A repetibilidade média das leituras, baseada nas análises em duplicata, foi de $91,5 \%$. Em adição, foram feitas novas análises em $32 \%$ da amostra, obtendo-se uma reprodutibilidade de $92,2 \%$ (AMORIM, 1995; RAMIRES et al., 2006; SABESP, 2007). Os dados obtidos foram tabulados e submetidos à análise estatística - ANOVA e Teste de Tukey a 5\%, objetivando-se verificar se existiam diferenças significantes entre os locais de captação e entre os pontos de coleta. 


\section{Resustados}

Foram analisadas amostras de água de 100 residências, com três pontos de coleta em cada, em cinco regiões da cidade de São José dos Campos, SP, com resultados contidos na Tabela 1.

Tabela 1. Análise da água de abastecimento de residências das zonas sul, leste, norte, central e oeste de São José dos Campos, SP, 2003.

Residências - concentração de Flúor (mg / I)

\section{Zona Sul}

\begin{tabular}{|c|c|c|c|c|c|c|c|c|c|c|c|c|c|c|c|c|c|c|c|c|}
\hline Ponto de coleta & 1 & 2 & 3 & 4 & 5 & 6 & 7 & 8 & 9 & 10 & 11 & 12 & 13 & 14 & 15 & 16 & 17 & 18 & 19 & 20 \\
\hline Cavalete & 0,8 & 0,8 & 0,8 & 0,8 & 0,9 & 0,9 & 0,8 & 0,9 & 0,9 & 0,8 & 0,8 & 0,9 & 0,8 & 0,9 & 0,8 & 0,8 & 0,8 & 0,8 & 0,8 & 0,9 \\
\hline Reservatório & 0,8 & 0,8 & 0,8 & 0,9 & 0,9 & 0,9 & 0,9 & 0,9 & 0,9 & 0,9 & 0,9 & 0,9 & 0,9 & 0,9 & 0,9 & 0,9 & 0,8 & 0,8 & 0,9 & 0,8 \\
\hline Filtro & 0,8 & 0,8 & 0,8 & 0,9 & 0,9 & 0,8 & 0,9 & 0,9 & 0,9 & 0,9 & 0,8 & 0,9 & 0,9 & 0,9 & 0,9 & 0,9 & 0,8 & 0,9 & - & 0,9 \\
\hline \multicolumn{21}{|c|}{ Zona Leste } \\
\hline Ponto de coleta & 1 & 2 & 3 & 4 & 5 & 6 & 7 & 8 & 9 & 10 & 11 & 12 & 13 & 14 & 15 & 16 & 17 & 18 & 19 & 20 \\
\hline Cavalete & 0,8 & 0,8 & 0,9 & 0,8 & 0,9 & 0,8 & 0,8 & 0,8 & 0,8 & 0,8 & 0,9 & 0,8 & 0,8 & 0,8 & 0,8 & 0,9 & 0,8 & 0,8 & 0,8 & 0,8 \\
\hline Reservatório & 0,8 & 0,9 & 0,9 & 0,9 & 0,9 & 0,9 & 0,8 & 0,8 & 0,9 & 0,8 & 0,9 & 0,8 & 0,8 & 0,8 & 0,8 & 0,9 & 0,8 & 0,9 & 0,8 & 0,8 \\
\hline Filtro & 0,8 & 0,9 & 0,9 & 0,9 & 0,8 & 0,8 & 0,9 & 0,8 & 0,9 & 0,9 & 0,9 & 0,8 & 0,8 & 0,8 & 0,9 & 0,9 & 0,8 & 0,8 & 0,8 & 0,8 \\
\hline \multicolumn{21}{|c|}{ Zona Norte } \\
\hline Ponto de coleta & 1 & 2 & 3 & 4 & 5 & 6 & 7 & 8 & 9 & 10 & 11 & 12 & 13 & 14 & 15 & 16 & 17 & 18 & 19 & 20 \\
\hline Cavalete & 0,8 & 0,8 & 0,8 & 0,8 & 0,8 & 0,8 & 0,9 & 0,8 & 0,8 & 0,8 & 0,9 & 0,8 & 0,8 & 0,8 & 0,9 & 0,8 & 0,9 & 0,8 & 0,8 & 0,8 \\
\hline Reservatório & 0,8 & 0,8 & 0,8 & 0,8 & 0,8 & 0,8 & 0,9 & 0,8 & 0,8 & 0,9 & 0,8 & 0,8 & 0,8 & 0,9 & 0,8 & 0,8 & 0,8 & 0,8 & 0,9 & 0,8 \\
\hline Filtro & 0,9 & 0,9 & 0,8 & 0,8 & 0,8 & 0,7 & 0,8 & 0,9 & 0,9 & 0,7 & 0,8 & 0,8 & 0,8 & 0,9 & 0,8 & 0,8 & 0,8 & 0,9 & 0,9 & 0,8 \\
\hline \multicolumn{21}{|c|}{ Zona Central } \\
\hline Ponto de coleta & 1 & 2 & 3 & 4 & 5 & 6 & 7 & 8 & 9 & 10 & 11 & 12 & 13 & 14 & 15 & 16 & 17 & 18 & 19 & 20 \\
\hline Cavalete & 0,6 & 0,7 & 0,8 & 0,8 & 0,7 & 0,7 & 0,7 & 0,7 & 0,6 & 0,6 & 0,7 & 0,7 & 0,7 & 0,7 & 0,7 & 0,7 & 0,6 & 0,7 & 0,7 & 0,7 \\
\hline Reservatório & 0,8 & 0,8 & 0,8 & 0,8 & 0,8 & 0,8 & 0,8 & 0,7 & 0,6 & 0,7 & 0,7 & 0,6 & 0,7 & 0,7 & 0,7 & 0,7 & 0,6 & 0,6 & 0,7 & 0,7 \\
\hline Filtro & 0,8 & 0,8 & 0,7 & 0,6 & 0,7 & 0,7 & 0,6 & 0,6 & 0,6 & 0,6 & 0,6 & 0,6 & 0,7 & 0,7 & 0,7 & - & 0,7 & 0,6 & 0,8 & 0,7 \\
\hline \multicolumn{21}{|c|}{ Zona Oeste } \\
\hline Ponto de coleta & 1 & 2 & 3 & 4 & 5 & 6 & 7 & 8 & 9 & 10 & 11 & 12 & 13 & 14 & 15 & 16 & 17 & 18 & 19 & 20 \\
\hline Cavalete & 0,8 & 0,8 & 0,8 & 0,9 & 0,8 & 0,9 & 0,9 & 0,8 & 0,8 & 0,9 & 0,9 & 0,8 & 0,8 & 0,8 & 0,8 & 0,8 & 0,8 & 0,7 & 0,6 & 0,8 \\
\hline Reservatório & 0,8 & 0,8 & 0,7 & 0,8 & 0,8 & 0,8 & 0,8 & 0,7 & 0,8 & 0,8 & 0,9 & 0,7 & 0,8 & 0,9 & 0,8 & 0,9 & 0,9 & 0,8 & 0,8 & 0,8 \\
\hline Filtro & 0,2 & 0,7 & 0,8 & 0,8 & 0,8 & 0,8 & 0,2 & 0,8 & 0,8 & 0,9 & 0,9 & 0,9 & 0,8 & 0,9 & 0,8 & 0,8 & 0,2 & 0,8 & 0,8 & 0,9 \\
\hline
\end{tabular}

Das 100 residências analisadas, duas foram excluídas por falha no armazenamento das amostras do ponto de coleta filtro.

Analisando-se a variação entre os pontos cavalete-reservatório, 13 casas (13,2\%) tiveram redução de 0,1mg/l, $24(24,4 \%)$ tiveram aumento de 0,1 mg/l, $2(2 \%)$ tiveram aumento de 0,2mg/l e 59 $(60,2 \%)$ não tiveram alteração.

Considerando a variação entre reservatório e filtro, 14 casas $(14,2 \%)$ tiveram redução de 0,1mg/l, $17(17,3 \%)$ tiveram aumento de 0,1 mg/l, 4 (4\%) tiveram redução de 0,2mg/l, 1 (\%) aumento de 0,2 mg/l e 59 (60,2\%) não tiveram alteração.

Os resultados de cada região foram submetidos à análise de variância (Anova) e os resultados estão apresentados na Tabela 2.

Tabela 2. Estatística descritiva (média \pm dp, mediana) dos dados de teor de flúor coletados em três pontos. Resultado do teste ANOVA de Kruskal-Wallis (nível de significância adotado $=5 \%$ ).

\begin{tabular}{lccccccc}
\hline Zona & \multicolumn{2}{c}{ Cavalete } & \multicolumn{2}{c}{ Reservatório } & Filtro & Anova \\
\hline A: Sul & $0,831 \pm 0,047$ & 0,83 & $0,873 \pm 0,045$ & 0,90 & $0,868 \pm 0,047$ & 0,90 & $\mathrm{p}=0,001$ \\
B: Leste & $0,820 \pm 0,041$ & 0,80 & $0,845 \pm 0,051$ & 0,80 & $0,845 \pm 0,051$ & 0,80 & $\mathrm{p}=0,058$ \\
C: Norte & $0,820 \pm 0,041$ & 0,80 & $0,820 \pm 0,041$ & 0,80 & $0,825 \pm 0,064$ & 0,80 & $\mathrm{p}=0,938$ \\
D: Central & $0,689 \pm 0,056$ & 0,70 & $0,715 \pm 0,076$ & 0,70 & $0,673 \pm 0,073$ & 0,70 & $\mathrm{p}=0,106$ \\
E: Oeste & $0,081 \pm 0,071$ & 0,80 & $0,805 \pm 0,060$ & 0,80 & $0,730 \pm 0,234$ & 0,80 & $\mathrm{p}=0,178$ \\
\hline Kruskal-Wallis & $\mathrm{p}=0,001$ & $\mathrm{p}=0,001$ & $\mathrm{p}=0,001$ \\
\hline
\end{tabular}

Na comparação entre as Zonas, para o Cavalete, foi efetuado o teste de comparação múltipla de Dunn (5\%) e verificou-se que a Central difere das outras zonas.

Na comparação entre as Zonas, para o Reservatório, foi efetuado o teste de comparação múltipla de Dunn (5\%) e verificouse que a Central difere das outras zonas e ainda, que a zona Sul difere das zonas Oeste e Central.

$\mathrm{Na}$ comparação entre as Zonas, para o Filtro, foi efetuado o teste de comparação múltipla de Dunn (5\%), quando se observou que a Central difere das outras zonas e ainda, que a zona Sul difere das zonas Oeste e Central.

Na comparação ente os pontos de Coleta, foi efetuado o teste de comparação múltipla de Tukey $(5 \%)$ para a zona Sul. Verificou-se que o Cavalete difere do Reservatório e do Filtro.

\section{Discussão}

Pela análise dos resultados em relação à quantidade de flúor presente nas amostras, notou-se que 207 (70\%) amostras das 298 analisadas tiveram seu nível de acordo com o que o Ministério da Saúde preconiza como ideal para a temperatura média anual da região, entre 0,6 e 0,8mg/l, mesmo na zona central, não constituindo, portanto, nem fator desencadeante nem predisponente de fluorose por si só (BRASIL, 2006; CASARIN, 2007; CURY, 2001; MASCARENHAS, 2000). 
Não houve evidência de alteração significativa dos níveis de flúor da água de abastecimento durante a passagem pelos reservatórios, pela tubulação e pelos filtros domésticos de carvão ativado, concordando com dados dos trabalhos de Amorim (1995), Ong, Willians e Holt (1996) e Vidal (2006). Houve residências em que foi notada redução no nível de flúor entre um ponto de coleta e outro, mas em outras esse nível se elevou, e quando a alteração ocorreu, foi na maioria da ordem de $0,1 \mathrm{mg} / \mathrm{l}$. Além disso, a maioria das casas manteve estáveis os índices de fluoreto, tanto durante a passagem cavalete-reservatório quanto do reservatório para o filtro.

Observou-se também que três casas da zona oeste tiveram redução acentuada durante a passagem do reservatório para o filtro. Essas casas foram novamente visitadas e averiguou-se que os moradores omitiram a informação que abasteciam seus filtros com água mineral adquirida em galões, com teor de flúor aquém da recomendada para conferir prevenção. Faz-se a ressalva que, se a água de abastecimento estiver sendo utilizada para o preparo de alimentos, enxágue da boca após a escovação, entre outras formas de contato, o proveito será mantido, conforme comprovado por Cury (2001) e Schulte, Rossbach e Tramini (2001).

Este resultado a menor nesses domicílios também evidencia confiabilidade dos resultados obtidos, uma vez que acusou prontatamente os desvios acentuados, propiciados não pela retenção dos filtros e sim pela aquisição de água em galões, prática cada vez mais abrangente em nossa sociedade de consumo, desconhecedora do potencial prejuízo para a saúde bucal em função de um teor de flúor insuficiente para uma efetiva prevenção de cárie.

A região central e sul foram as que diferiram das demais estatisticamente, com um menor teor de flúor na água de abastecimento que chega às residências na zona central e maior na zona sul. Mas é importante salientar que, mesmo nessas regiões, não houve variação evidente de retenção de flúor durante o percurso da água nas residências, bem como não tornou os índices de flúor das amostras impróprios ou inadequados ao fim a que se propõem.

\section{Conclusão}

Com base nos resultados obtidos, concluiu-se que:

- o teor de flúor da água de abastecimento do município de São José dos Campos, SP não sofreu variação no período avaliado, mantendo teores considerados adequados para a região e ideais para a prevenção de cáries;

- não houve variação significativa no teor de flúor entre os pontos de coleta avaliados - cavalete, reservatório e filtro;

- embora tenham ocorrido variações entre as zonas avaliadas, com teor mais elevado na zona sul e menor na zona central, os teores permaneceram dentro dos padrões recomendados, na atualidade, para a região;

- $\quad$ as residências que utilizavam água de consumo não proveniente da rede de abastecimento (ponto de coleta 3), apresentaram teor de flúor de 0,2 $\mathrm{mg} / \mathrm{l}$, menor que o preconizado para este município e aquém do necessário para conferir proteção contra as cáries.

Agradecimento ao professor Ivan Balduci, responsável pela análise estatística do trabalho.

\section{Referências}

AMORIN, J. B. O. Estudo Comparativo do Teor de Flúor Encontrado na Rede de Abastecimento Público, Reservatórios Domiciliares e Filtros Domésticos em Estudo Potenciométrico. São José dos Campos: Faculdade de Odontologia de São José dos Campos, Departamento de Ciências Fisiológicas, 1995. [Trabalho com premiação do Prêmio Kolynos 1992.]

BERNI, D. Á. Técnicas de Pesquisa em Economia. São Paulo: Saraiva, p. $161-163,2002$.

BRASIL. Lei no 6050, de 24 de maio de 1974. Dispõe sobre a Fluoretação de Água em Sistemas de Abastecimento quando Existir Estação de Tratamento. Diário Oficial [da] República Federativa do Brasil, Poder Executivo, Brasília, DF, 27 maio 1974.

BRASIL. Decreto o 76.872 de 22 de dezembro de 1975. Regulamenta a Lei oㅡ 6050 de 24 de maio de 1974. Diário Oficial [da] República Federativa do Brasil, Poder Executivo, Brasília, DF, 23 dez. 1975.

BRASIL. Ministério da Saúde. Portaria no 635/Bsb, de 25 de dezembro de 1975. Aprova as Normas e Padrões sobre a Fluoretação da Água dos Sistemas Públicos de Abastecimento, Destinada ao Consumo Humano. Diário Oficial [da] República Federativa do Brasil, Poder Executivo, Brasília, DF, 30 jan. 1976.

BRASIL. Ministério da Saúde. Portaria n.ำ 518, de 25 de março de 2004. Estabelece os Procedimentos e Responsabilidade Relativa ao Controle e Vigilância da Qualidade da Água para o Consumo Humano e seu Padrão de Potabilidade, e dá outras Providências. Diário Oficial [da] República Federativa do Brasil, Poder Executivo, Brasília, DF, 26 mar. 2004.

BRASIL. Ministério da Saúde. Fundação Nacional de Saúde. Programa Brasil Sorridente. A Saúde Bucal Levada a Sério: Sub-componente Fluoretação da Água: Cartilha do Gestor. Brasília, DF, 2006.

BROWN, M. D; AARON, G. The Effect of Point-of-Use Water Conditioning Systems on Community Fluoridated Water. Pediatr. Dent., Chicago, v.13, n. 1, p. 35-38, Jan./Feb. 1991.

CASARIN, R. C. V. et al. Concentração de Fluoreto em Arroz, Feijão e Alimentos Infantis Industrializados. Rev. Saúde Pública, São Paulo, v. 41, n. 4, p. 549-556, ago. 2007.

CURY, J. A. Uso do Flúor e Controle da Cárie como Doença. In: BARATIERI, L. N. et al. Odontologia Restauradora: Fundamentos e Possibilidades. São Paulo: Liv. Santos, Cap. 4, p. 33-68, 2001.

EDELSTEIN, B. L. et al. Comparison of Colorimeter and Electrode Analysis of Water Fluoride. Pediatr. Dent., Chicago, v. 14, n. 1, p. 47-49, Jan.Feb. 1992.

GLASS, R. G. Water Purification Systems and Recommendations for Fluoride Supplementation. J. Dent. Child., Chicago, v. 58, no. 5, p. 405408, Sept./Oct. 1991.

JOBSON, M. D. et al. The Effects of Water Filtration Systems on Fluoride: Washington, D. C. Metropolitan Area. ASDC J. Dent. Child., Chicago, v. 67 , n. 5, p. 350-354, Sept./Oct. 2000.

KOZLOWSKI, F. C; PEREIRA, A. C. Métodos de Utilização de Flúor Sistêmico. In: PEREIRA, A. C. et al. Odontologia em Saúde Coletiva. Porto Alegre: Artmed, p. 265-74 2003.

MASCARENHAS, A. K. Risk Factors for Dental Fluorosis: a Review of the Recent Literature. Pediatr. Dent., Chicago, v. 22, no. 4, p. 269-277, July/Aug. 2000.

ONG, Y. S.; WILLIANS, B.; HOLT, R. The Effect of Domestic Water Filters on Water Fluoride Content. Br. Dent. J., London, v. 181, no. 2, p. 56-63, July 1996.

RAMIRES, I. et al. Heterocontrole da Fluoretação da Água de Abastecimento Público em Bauru, SP, Brasil. Rev. Saúde Pública, São Paulo, v. 40, no. 5, p. 883-889, Oct. 2006.

ROBINSON, S. N; DAVIES, E. H; WILLIANS, B. Domestic Water Treatment Appliances and the Fluoride Ion. Br. Dent. J., London, v. 171, no. 3-4, p. 91-93, Aug. 1991.

SABESP. Disponível em www.sabesp.com.br. Acesso em 16 de dez. 2007.

SCHULTE, A; ROSSBACH, R; TRAMINI, P. Association of Caries Experience in 12 Year-Old Children in Heidelberg, Germany, and Montpellier, France, with Different Caries Preventive Measures. Community Dent. Oral Epidemiol., Copenhagen, v. 29, no. 5, p. 354-361, Oct. 2001.

VIDAL, S. G. et al. Heterocontrole da Fluoretação da Água de Abastecimento Público do Município de Torres/RS. Stomatos, Canoas, v. 12, n. 22, p. 5-9, jan./jun. 2006.

WORLD HEALTH ORGANIZATION. Fluorides and Oral Health. Geneva, p. 37, 1994. [Technical report series, 846]. 